\title{
SISTEM INTEGRASI DATA MUSRENBANG DESA BERBASIS WEB
}

\author{
Rosmawati Tamin ${ }^{1}$, Muhammad Sarjan' ${ }^{2}$, Riska. $\mathbf{R}^{3}$ \\ Program Studi Sistem Informasi ${ }^{123}$ \\ Universitas Al Asyariah Mandar \\ Jl. Budi Utomo No. 2, Sulawesi Barat, Indonesia \\ riska.r0371@gmail.com ${ }^{1}$
}

\begin{abstract}
ABSTRAK
Musyawarah Perencanaan Pembangunan (Musrenbang) sebagai agenda tahunan dalam rangka menyusun rencana pembangunan nasional dan rencana pembangunan daerah. Masalah yang terjadi pada Desa/Kelurahan di Kecamatan Wonomulyo yaitu, proses rekapitulasi data Musrenbang masih manual yang mana data masih dikerjakan dengan cara diketik dan disimpan memakai Microsoft Excel. Akibatnya, banyak data Musrenbang yang sering hilang dan banyak salah dalam memasukkan data serta bentuk pengelolaan data masih dilakukan secara konvensional. Sistem integrasi data dibangun dengan menggunakan metode waterfall, menggunakan bahasa pemograman PHP dan Database MysQL. Solusi yang ditawarkan adalah sebuah website yang terhubung dengan beberapa instansi yang terlibat sehingga proses input, dan penyajian data dapat disajikan dalam satu proses. begitupun daftar rencana kerja dan usulan pembangunan desa serta melihat status usulan dengan cepat. Hasil penelitian ini adalah sebuah desain sistem informasi yang bertujuan untuk mengolah data hasil musyawarah perencanaan pembangunan desa sehingga mempercepat proses pembuatan laporan musrenbang desa dan sebagai wadah penyampaian untuk mengusulkan hasil musyawarah perencanaan pembangunan desa berupa rencana kerja dan usulan pembangunan desa yang nantinya akan bisa dipantau langsung oleh Kecamatan Wonomulyo dan Balitbangren Kab. Polewali Mandar.
\end{abstract}

Kata Kunci : Sistem Informasi, Musrenbang Website, Desa/Kelurahan.

\begin{abstract}
Development Planning Consultation (Musrenbang) as an annual agenda in the framework of compiling national development plans and regional development plans. Problems that occur in the Village / Kelurahan in Wonomulyo District, namely, the process of recapitulation of Musrenbang data is still manual where data is still being worked out by typing and storing using Microsoft Excel. As a result, much of the Musrenbang data is often lost and a lot of errors in entering data and forms of data management are still done conventionally. The data integration system is built using the waterfall method, using the PHP programming language and MysQL Database. The solution offered is a website that is connected with several agencies involved so that the input process, and presentation of data can be presented in one process. as well as a list of work plans and village development proposals and see the status of proposals quickly. The results of this study are an information system design that aims to process the data from village development planning deliberations so as to accelerate the process of making village musrenbang reports and as a delivery forum to propose the results of village development planning meetings in the form of work plans and village development proposals which will be monitored directly by Wonomulyo District and Balitbangren District. Polewali Mandar.
\end{abstract}

Keywords: Information System, Musrenbang Website, District 


\section{PENDAHULUAN}

Musyawarah Perencanaan Pembangunan (Musrenbang) adalah agenda tahunan dalam rangka menyusun rencana pembangunan nasional dan rencana pembangunan daerah. Musrenbang dilaksanakan secara berjenjang dari tingkat bawah hingga atas. Pelaksanaan musrenbang diawali dengan musrenbang kelurahan, kemudian dilanjutkan dengan musrenbang kecamatan, lalu musrenbang pada tingkat kabupaten/kota kemudian musrenbang provinsi, selanjutnya pelaksanaan musrenbang terakhir yaitu musrenbang tingkat nasional [1].

Masalah yang terjadi pada Desa/kelurahan, Kecamatan Wonomulyo dan Balitbangren Kab. Polewali Mandar dimana bentuk pengelolaan RKPDes masih dilakukan secara konvensional, yaitu berkas disimpan dilemari arsip, apabila dibutuhkan berkas akan sulit untuk didapatkan karna semakin banyaknya berkas yang menumpuk setiap tahunnya. Proses tersebut apabila dilakukan secara manual, mempunyai banyak kelemahan, selain membutuhkan waktu yang lama, keakuratannya juga kurang dapat diterima, karena kemungkinan kesalahan sangat besar. Dengan dukungan teknologi informasi yang ada sekarang ini, pekerjaan pengelolaan data dengan cara manual dapat digantikan dengan suatu sistem informasi. Selain lebih cepat dan mudah, pengelolaan data juga menjadi lebih akurat.

Berdasarkan pemaparan latar belakang diatas, penulis mengangkat judul "Sistem Informasi

\section{Musrenbang Desa Berbasis Website"}

\section{TINJAUAN PUSTAKA}

\subsection{Sistem Informasi Manajemen}

Sistem informasi manajemen merupakan kumpulan dari sub-sub sistem yang saling berhubungan satu sama lain dan bekerja sama secara harmonis untuk mencapai satu tujuan yaitu mengolah data menjadi informasi yang diperlukan oleh manajemen dalam proses pengambilan keputusan saat melaksanakan fungsinya [2].

Dengan SIM maka manajemen dan semua unsur manajemen di setiap level dapat memiliki atau mengakses informasi yang cermat dan tepat waktu sehingga memudahkan hubungan dan koordinasi dengan level manajemen lainnya baik yang menjadi atasannya maupun bawahannya, baik dalam bentuk pelaporan, maupun evaluasi dan pengendalian, serta sangat berguna bagi kepentingan pelayanan kepada pelanggan [3].

\subsection{Konsep Dasar Web}

1. Internet kependekan dari (Interconnected Network) merupakan sistem global dari seluruh jaringan komputer yang saling terhubung menggunakan standar Internet Protocol Suite (TCP/IP) untuk melayani miliaran pengguna diseluruh dunia. Dengan begitu maraknya informasi dan kegiatan di internet, menjadikan internet seakan - akan sebagai dunia tersendiri yang tanpa batas. Dunia dalam internet disebut juga dunia maya (cyberspace) [4].

2. Website merupakan sebuah media informasi yang ada di internet. Website adalah kumpulan dari halaman-halaman situs, yang biasanya terangkum dalam sebuah domain atau sub domain, yang tepatnya berada di dalam World Wide Web (WWW) di internet. Sebuah halaman web adalah dokumen yang ditulis dalam format HTML (Hyper Text Markup Language), yang hampir selalu bisa diakses melalui HTTP, yaitu protokol yang menyampaikan informasi dari server website untuk menampilkan kepada para pemakai melalui web browser. Semua publikasi dari website-website tersebut dapat membentuk sebuah jaringan informasi yang sangat besar [5].

3. PHP atau kependekatan dari Hypertext Preprocessor adalah salah satu bahasa pemrograman open source yang sangat cocok atau dikhususkan untuk pengembangan web dan dapat ditanamkan pada sebuah skripsi HTML. Bahasa PHP dapat dikatakan menggambarkan beberapa bahasa pemrograman seperti C, Java, dan Perl serta mudah untuk dipelajari.PHP merupakan bahasa scripting server-side, dimana pemrosesan datanya dilakukan pada sisi server. Sederhananya, serverlah yang akan menerjemahkan skrip program, baru kemudian hasilnya akan dikirim kepada clientyang melakukan permintaan [6].

4. My Structured Query Language (MySQL) adalah sebuah program pembuat dan pengelola database atau sering disebut Databse Management System (DBMS). Sifat dari DBMS ini adalah open source. MySQL juga merupakan program pengakses database yang bersifat jaringan, sehingga dapat digunakan untuk aplikasi multi user (banyak pengguna) [7].

5. Xampp adalah perangkat lunak bebas, yang mendukung banyak sistem operasi, merupakan kompilasi dari beberapa program. Fungsinya adalah sebagai server yang berdiri sendiri (localhost) yang terdiri atas program Apache HTTP Server, MySQL database, dan penerjemahan bahasa yang ditulis dengan bahasa pemrograman PHP dan Perl. Nama $X A M P P$ merupakan singkatan dari X (empat sistem operasi apapun), Apache, MySQL, PHP dan Perl. Sistem kerja dari PHP diawali dengan permintaan yang berasal dari halaman website oleh browser [8]. 


\subsection{Kerangka Fikir}

Kerangka kerja yang diusulkan dapat dilihat pada Gambar berikut.

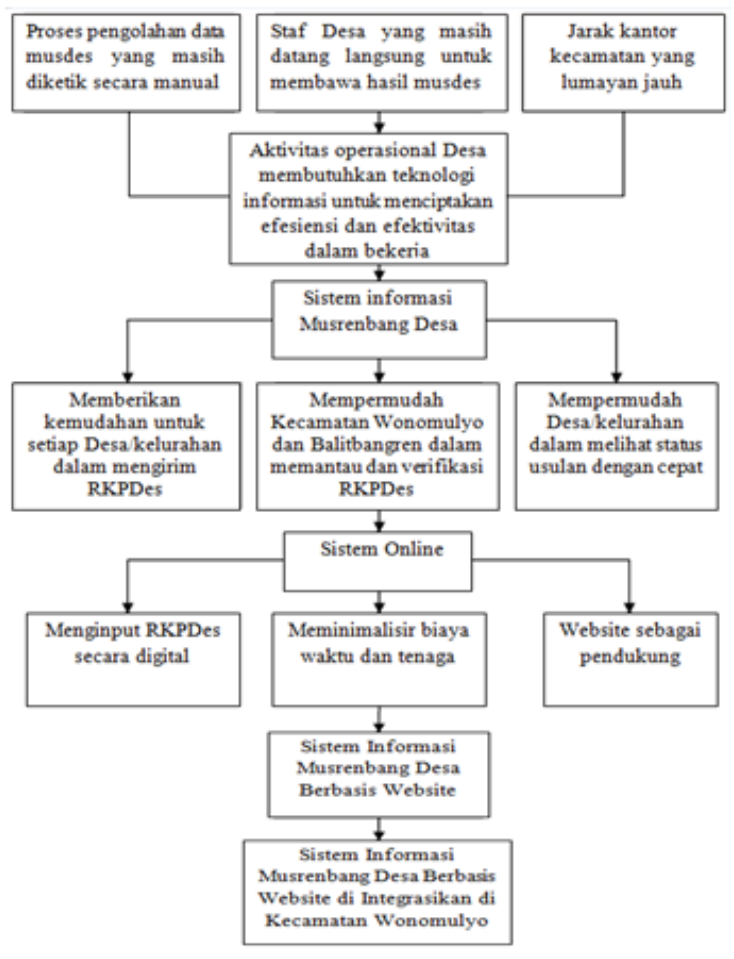

Gambar 2.1. Kerangka Pikir

Penjelasan kerangka fikir :

1. Masalah

Proses pengolahan data musrenbang Desa/kelurahan yang diketik secara manual kemudian staf Desa/kelurahan akan datang langsung ke kecamatan untuk membawa RKPDes yang berisi Rencana Kerja dan Usulan Pembangunan Desa dan masih terkendala dengan jarak kantor Kecamatan yang lumayan jauh. Di Kecamatan Staf Bidang PMD akan mengetik ulang Usulan Pembangunan Desa di Ms. Exel, setelah diperiksa terdapat permasalahan dimana format usulan musrenbang tiap desa berbeda-beda, pengurutan data usulan masih kurang tertata dengan baik, dan data kurang lengkap

2. Solusi dan manfaat

Dengan adanya sistem informasi musrenbang desa berbasis web dapat menyelesaikan permasalahan yang ada dan memberikan kemudahan untuk setiap staf Desa/kelurahan dalam mengirim Rencana Kerja dan Usulan Pembangunan Desa

3. Teknologi

Sistem informasi musrenbang desa web diakses secara online menggunakan teknologi web sistem.

4. Implementasi

Aplikasi Sistem Informasi Musrenbang

Desa berbasis web di implementasikan di setiap
Desa/kelurahan di Kecamatan Wonomulyo, Kecamatan Wonomulyo Bidang PMD, dan Balitbangren Bidang Perencanaan Pengendalian Program.

\subsection{Tahapan Penelitian}

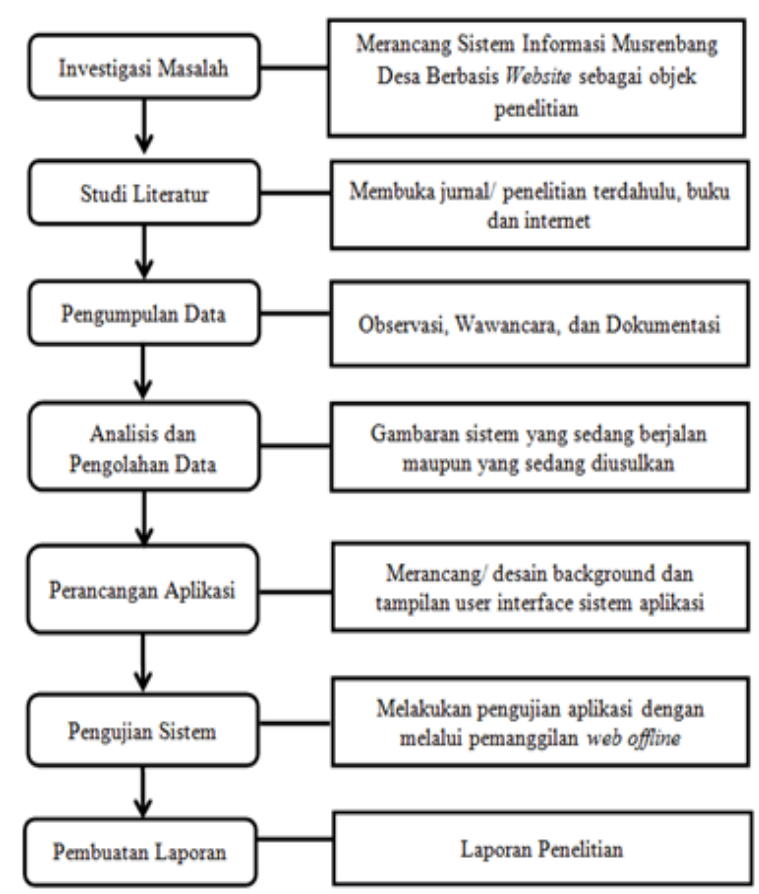

Gambar 3.1. Tahapan Penelitian

Berikut Penjelasan Tahapan Penelitian

1. Investigasi Masalah

Pada tahapan ini dilakukan investigasi masalah untuk menentukan suatu sistem yang akan dijadikan sebagai objek penelitian.

2. Study Literatur

Membaca dan mengumpulkan bahan referensi baik dari buku, jurnal, internet maupun informasi langsung dari lokasi penelitian.

3. Pengumpulan Data

Mengumpulkan semua data yang telah diperoleh dari proses yang telah dilakukan, baik dari observasi maupun hasil wawancara dari kantor Desa/Kelurahan, Kec. Wonomulyo, Dan Balitbangren Kab. Polewali Mandar.

4. Analisis dan Pengolahan data

Gambaran sistem yang sedang berjalan dan menentukan sistem yang akan diusulkan.

5. Perancangan aplikasi sistem informasi musrenbang desa

Merancang/ desain background dan tampilan user interface sistem aplikasi.

6. Pengujian sistem

Melakukan pengujian aplikasi setelah rancangan dibuat, sistem akan di uji melalui pemanggilan web offline dengan cara mengetikkan localhost pada browser seperti google chrome atau mozilla. 


\section{Pembuatan laporan}

Pada tahapan ini dilakukan pembuatan laporan yang disusun berdasarkan hasil penelitian .

\subsection{Teknik Pengumpulan Data}

Pengumpulan data dapat dilakukan dengan berbagai setting, berbagai sumber dan berbagai cara. Pengumpulan data dapat menggunakan sumber primer dan sumber sekunder. Sumber primer adalah sumber data yang langsung memberikan data kepada pengumpul data, dan sumber sekunder merupakan sumber yang tidak langsung memberikan data kepada pengumpul data [9].

1. Metode Observasi (Pengamatan Langsung)

Metode ini dilakukan untuk memperoleh data atau gambaran serta keterangan terhadap sistem yang sedang berjalan. Hasil dari observasi peneliti menunjukkan bahwa sistem yang berjalan kurang efektif karena masih dilakukan dengan cara manual.

2. Metode Wawancara

Penulis melakukan tanya jawab secara tatap muka langsung dengan pihak yang mengurusi data musrenbang, baik dari Desa/kelurahan, Kecamatan Wonomulyo dan Balitbangren Kab. Polewali Mandar, guna mendapatkan data-data dan keterangan yang diperlukan.

3. Metode Dokumentasi

Dokumentasi yaitu pengumpulan data yang dilakukan dengan cara mengumpulkan dokumen-dokumen yang berkaitan dengan judul penelitian penulis.

\subsection{Teknik Analisis Data}

Analisis data adalah proses menghimpun atau mengumpulkan data dengan tujuan untuk menemukan dan memperoleh informasi sehingga mampu untuk memberikan saran, menyimpulkan dan mendukung pembuatan keputusan. Tehnik analisis data yang dilakukan antara lain:

1. Menyiapkan segala hal yang dibutuhkan pada saat penelitian

2. Mengidentifikasi masalah pada sistem yang lama/berjalan.

3. Menganalisis dan memahami kerja dari sistem yang lama/berjalan.

4. Mengumpulkan beberapa data yang dibutuhkan dari sistem yang telah berjalan.

5. Membuat, merancang dan membangun sistem informasi musrenbang desa berbasis web.

\subsection{Kerangka Sistem}

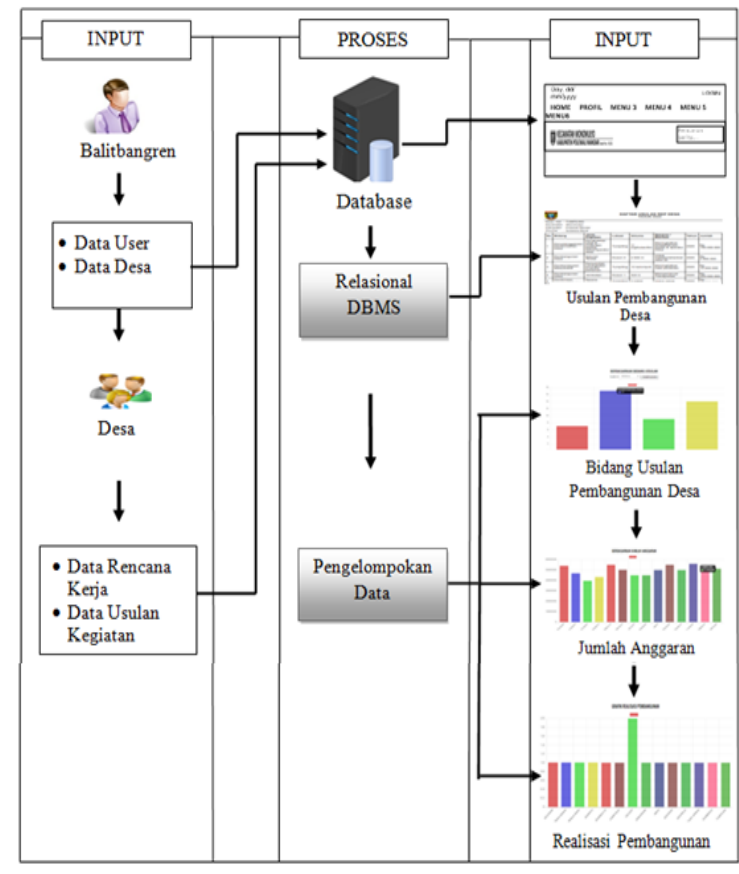

Gambar 3.2. Kerangka Sistem

Penjelasan Kerangka Sistem :

1. Pada proses input admin Balitbangren login ke web sistem untuk menginput data user dan data desa, agar desa bisa mengakses halaman untuk menginput dan mengirim Rencana Kerja Dan Usulan Pembangunan Desa yang nantinya akan dipantau langsung oleh Kecamatan Wonomulyo dan Balitbangren Kab. Polewali Mandar yang akan di proses melalui database $M y S Q L$ dengan menggunakan aplikasi yang berbasis website.

2. Output yang dihasilkan berupa data usulan pembangunan Desa/kelurahan yang dilengkapi dengan grafik bidang usulan pembangunan terbanyak, jumlah anggaran terbanyak yang diusulkan oleh Desa/kelurahan dan jumlah usulan pembangunan setiap Desa/kelurahan yang sudah terealisasi

\subsection{Hasil Penelitian}

Penelitian ini telah berhasil membangun sistem informasi musrenbang desa berbasis web, yang akan mempermudah desa dalam mengusulkan rencana kerja dan usulan pembangunan desa yang nantinya akan dipantau langsung oleh Kecamatan Wonomulyo dan Balitbangren Kab. Polewali Mandar, adapun gambaran infrastruktur system s sebagai berikut. 


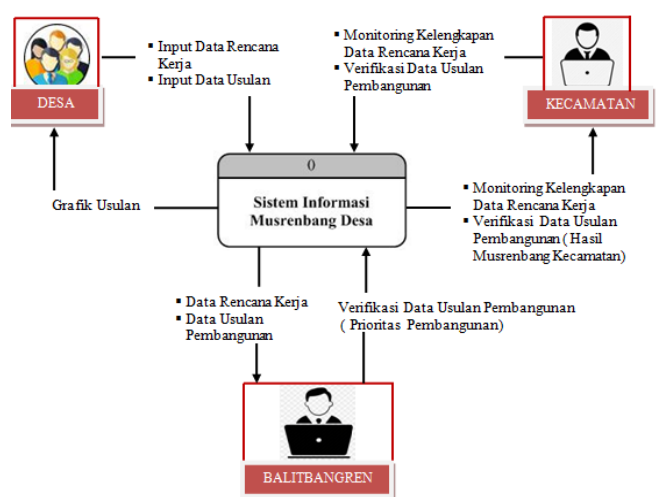

Gambar 4.1. Infrastruktur Sistem

\subsection{Perancangan Antarmuka}

1. Status Usulan Renja dan Usulan

Halaman dibawah ini akan tampil ketika Desa/kelurahan berhasil mengirim rencana kerja dan usulan pembangunan desa.

\begin{tabular}{|l|l|l}
\hline Status Laporan & Keterangan & Action \\
\hline TERKIRIM & & C 道 \\
\hline
\end{tabular}

Gambar 4.2. Status Rencana Kerja

\begin{tabular}{|c|c|c|}
\hline Status - & Mlasain & Action \\
\hline TERRKIRIM & & $\Xi$ 而 \\
\hline
\end{tabular}

Gambar 4.3. Status Usulan

2. Verifikasi Renja dan Usulan

Halaman dibawah ini digunakan oleh kecamatan wonomulyo untuk melakukan monitoring dan verifikasi kelengkapan data rencana kerja sebelum diproses ke Balitbangren dan melakukan verifikasi usulan berdasarkan hasil musrenbang kecamatan yang diterima dan ditolak.

\begin{tabular}{|l|l|c|}
\hline Status Laporan & Keterangan & Action \\
\hline LENGKAP & Sesuai & Q \\
\hline
\end{tabular}

Gambar 4.4. Status Verifikasi Renja

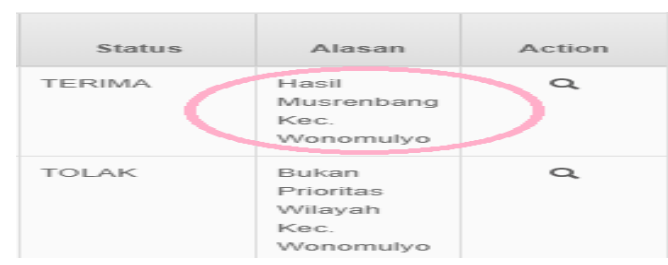

Gambar 4.5. Status Verifikasi Usulan

3. Verifikasi Renja dan Usulan

Halaman dibawah ini digunakan oleh admin Balitbangren untuk melakukan verifikasi rencana kerja dan usulan pembangunan desa berdasarkan prioritas pembangunan.

\begin{tabular}{|l|l|c|}
\hline Status Laporan & Keterangan & Action \\
\hline ACC $)$ & Sesuai & Q \\
\hline
\end{tabular}

Gambar 4.6. Verifikasi Renja

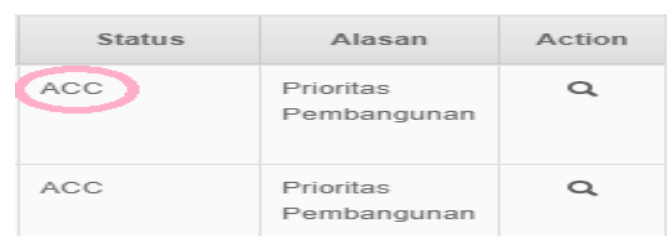

Gambar 4.7. Status Verifikasi Usulan

4. Output Grafik Usulan

Berrikut ini merupakan halaman output grafik usulan hasil dari penginputan dari Desa/kelurahan berdasarkan bidang usulan , jumlah anggaran terbanyak yang diusulkan oleh Desa/kelurahan, dan jumlah usulan pembangunan setiap Desa/kelurahan yang sudah terealisasi.

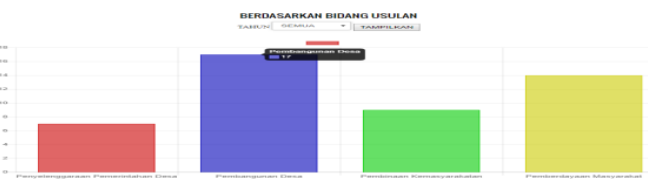

Gambar 4.8. Output Grafik Bidang
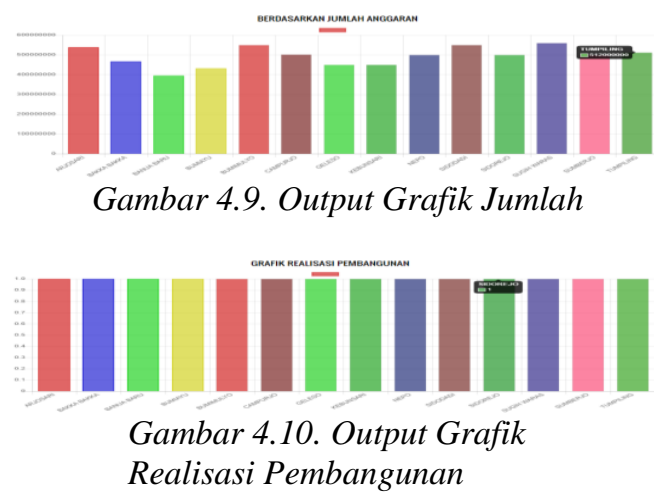

5.1. KESIMPULAN

Berdasarkan hasil penelitian yang telah dilakukan mulai dari awal hingga proses pengujian terhdap Aplikasi Sistem Informasi Musrenbang Desa Berbasis Web maka dapat disimpulkan bahwa dengan adanya sistem ini dapat mempercepat proses pembuatan laporan musrenabng desa sehingga meminimalisisr biaya, waktu dan tenaga, mampu membantu menyeragamkan format usulan pembangunan desa dan sebagai wadah penyampaian untuk mengusulkan hasil musyawarah desa berupa renja dan usulan pembangunan desa. 


\section{Daftar Pustaka}

[1] Azhar, F. (2015). Partisipasi Masyarakat Dalam Musyawarah Perencanaan Pembangunan ( MUSRENBANG ) di Kelurahan Pegirian Kecamatan Semampir Kota Surabaya, 3, 67-68.

[2] Azhar Susanto. (2017). Sistem Infromasi Manajemen konsep dan pengembangan secara terpadu. bandung : Lingga jaya.

[3] Meirawan, D. A. T. dan D. (2013). Berbasis Teknologi Informasi Di Sekolah Dasar. Implementasi Sistem Informasi Manajemen Akademik Berbasis Teknologi Informasi Di Sekolah Dasar, (1), 61-72.

[6] Firman, A., Wowor, H., \& Najoan, X. (2016). Sistem Informasi Perpustakaan Berbasis Web Application. Jurnal Sistem Informasi Bisnis, 1(2), 66-77.

[7] Alex Fahrudin, Bambang Eka Purnama, B. K. R. (2011). Pembangunan Sistem Informasi Layanan Haji Berbasis Web Pada Kelompok Bimbingan Ibadah Haji. Speed, 9330(1), 63-71.

[8] Palit, R. V, Rindengan, Y. D. Y., \& Lumenta, A. S. M. (2015). Rancangan Sistem Informasi Keuangan Berbasis Web Di Jemaat GMIM Bukit Moria Malalayang. E-Journal Teknik Elektro Dan Komputer Vol, 4(7), 1-7.

[4] Sindi, R. A. L. F. K. H. (2015). Sistem Informasi Produk Dan Data Calon Jamaah Haji Dan Umroh Pada Pt. Travellindo Lusiyana Banjarmasin Berbasis Web. Jurnal POSITIF, 1(1), 1-13.

[9] Sugiyono. (2014). Teknik Pengumpulan Data Metodologi Penelitian. Bandung: $C V$ Alfabeta, 1-3.

[5] Trimarsiah, Y., \& Arafat, M. (2017). Analisis Dan Perancangan Website Sebagai Sarana, 19, 1-10. 